\title{
Pode ser... Poderia ser... O uso de modalizações na escrita acadêmica
}

\section{Can be... Could be... The use of Modalizations in Academic Writing}

Maria Otilia Guimarães Ninin*

Pontifícia Universidade Católica de São Paulo - PUC-SP

Universidade Paulista - UNIP

São Paulo - São Paulo / Brasil

RESUMO: Objetiva-se, neste artigo, discutir, com base na teoria linguística SistêmicoFuncional (HALLIDAY, 1985, 1994; HALLIDAY e MATTHIESSEN, 2004); na teoria da Avaliatividade (MARTIN, 2000; MARTIN e WHITE, 2005; WHITE, 2003, 2010), mais especificamente no sistema de Engajamento; e na perspectiva de Hengeveld $(1988,1989,2004)$ sobre modalidade, discutir o uso, por autores mestrandos e doutorandos em Letras/Linguística, da modalidade realizada pelo verbo "poder" e suas formas derivadas, na construção de estratégias discursivas. Considerou-se um corpus de 40 teses e 40 dissertaçôes produzidas entre 2008 e 2011, coletadas de sites de universidades brasileiras públicas e privadas. Os resultados revelaram ausência de critério na escolha do recurso de modalidade com o modal "poder", indicando responsabilidade ora do autor do texto, ora dos autores por ele citados, deixando, porém, transparecer diferentes significados em função de sua relação com outros elementos do discurso e do contexto.

PALAVRAS-CHAVE: modalidade, escrita acadêmica, linguística sistêmicofuncional

ABSTRACT: This paper, based on the theory of Systemic Functional Linguistics (HALLIDAY, 1985, 1994; HALLIDAY and MATTHIESSEN, 2004); on Appraisal Theory (MARTIN, 2000; MARTIN and WHITE, 2005; WHITE, 2003, 2010), more specifically on the Engagement system; and on Hengeveld's $(1988,1989,2004)$ perspective on modality, aims to discuss the use, by authors of masters and doctoral degrees in the field of linguistics, of modal forms stemming from the verb "can" and its derivatives in the construction of discursive strategies. This study analyzed a corpus of 40 theses and 40 dissertations produced between 2008 and 2011, collected from websites of Brazilian public and private universities.

* otilianinin@terra.com.br

Coordenadora e professora da pós-graduação lato sensu "Língua Portuguesa e Literatura" - UNIP-SP; professora da COGEAE PUC-SP. Doutora em Linguística Aplicada e Estudos da Linguagem pela PUC-SP. 
The findings reveal an absence of criteria in choosing the modality resource of the modal verb "can", indicating responsibility either on the part of the author of the text or of the authors cited by him, allowing for different meanings to emerge due to the verb's relation to other elements within the discourse and within the context. KEYWORDS: modality, academic writing, systemic-functional linguistics

\section{Introdução}

Objetiva-se, neste artigo, discutir, com base na Teoria Linguística Sistêmico-Funcional (HALLIDAY, 1994; HALLIDAY e MATTHIESSEN 2004), na Teoria da Avaliatividade (MARTIN e WHITE, 2005) e na perspectiva de Hengeveld $(1988,1989,2004)$ sobre modalidade, o uso, por autores mestrandos e doutorandos em Letras/Linguística, do modal "poder" e suas formas derivadas. Justifica-se a discussão em função da necessidade de compreensão sobre o modo como um texto é produzido em contexto acadêmico e como seu autor, por meio do discurso, projeta a si próprio na comunidade discursiva com a qual está envolvido, revelando a influência dos contextos de situação e de cultura em seus enunciados. No contexto universitário, isso se dá justamente na escrita acadêmica, uma das atividades mais valorizadas por estudantes de pós-graduação, que lhes permite participar das práticas sociais acadêmicas e posicionar-se em relação aos seus pares, revelando modos de engajamento com seus leitores, com a área específica de conhecimento e com outros autores reconhecidos como produtores de conhecimento científico.

Dado o grande movimento de expansão editorial atual na área científica, decorrente de exigências dos órgãos de fomento à pesquisa no Brasil por maior produção de artigos nas diversas áreas do conhecimento, tem crescido a preocupação de pesquisadores e docentes universitários em relação à escrita acadêmica, principalmente de estudiosos da área da linguagem (MOTTAROTH, 2001, 2002, 2006; MOTTA-ROTH e HENDGES, 2010; MOTTA-ROTH e LOVATO, 2011; FIAD, 2011; UYENO, 2009; FIGUEIREDO e BONINI, 2006; BESSA e BERNARDINO, 2011), que nem sempre veem nos textos produzidos por alunos a qualidade esperada.

Estudantes de graduação e pós-graduação, por sua vez, têm revelado grande angústia frente à produção de um texto acadêmico que possa ser considerado pela comunidade discursiva à qual pertencem. Muitos estudos realizados em diferentes áreas, desde a filosofia e psicologia, preocupadas com o envolvimento do sujeito numa perspectiva identitária (OLIVEIRA, 2011), 
aos embasados em diversas correntes linguísticas, com foco ora no gênero textual resenha (BEZERRA, 2002; WILSON e ABREU, 2010; MENDES, 2010; VIAN JR. e IKEDA, 2009), ora na introdução de trabalhos acadêmicos (SILVA, 2009), nos movimentos retóricos (MOTTA-ROTH, 2001, 2002, 2006; MACEDO e PAGANO, 2011), ou ainda na organização argumentativa (SOUZA e BESSA, 2011), alertam quanto à necessidade de reflexão sobre o ensino da escrita acadêmica e de discussão sistematizada sobre estratégias específicas para o aprendizado desses textos na academia.

Embora essa discussão mostre-se em efervescência, pouco se tem discutido sobre características específicas de dissertações e teses quanto aos modos de engajamento do autor em relação a outras vozes que povoam seu texto. Considerando-se o fato destes serem produzidos por alunos com conhecimentos mais avançados em sua área específica, poderíamos pressupor que conhecessem a função social, a organização retórica e as características linguísticas dos gêneros textuais acadêmicos. No entanto, como professora em curso de Letras, graduação e pós-graduação, ao orientar a escrita, em disciplinas voltadas à produção do texto acadêmico, tenho observado a dificuldade dos estudantes em elaborar a desafiante seção de revisão de literatura, justamente por esta exigir habilidades complexas de síntese e análise a partir de múltiplas fontes, sustentadas por uma argumentação que exige posicionamento crítico do autor.

Em pesquisa anterior (NININ, 2012), discuti o engajamento do autor ao apresentar, na seção teórica de dissertações em Letras/Linguística, vozes de autores citados como referência. Na perspectiva sistêmico-funcional dos estudos de Avaliatividade, mais especificamente Engajamento (MARTIN e WHITE, 2005), o foco recaiu nos modos de reconhecer o discurso do outro, recurso dos mais utilizados por autores do texto acadêmico. Tal investigação permitiu-me também observar o uso indiscriminado do modal "poder", ficando a cargo do leitor a decisão sobre qual ou quais probabilidades / possibilidades / obrigaçóes esse uso estaria indicando: se atribuídas à voz autoral ou a uma voz externa. Assim, considera-se, para este estudo, um corpus de 40 teses e 40 dissertaçóes produzidas entre 2008 e 2011, coletadas de sites de universidades brasileiras públicas e privadas, submetidas ao programa computacional WordSmith Tools (SCOTT, 2009), a partir do qual foram selecionados e discutidos enunciados com o uso do modal "poder".

Inicialmente, uma breve revisão dos conceitos mais relevantes ao estudo é apresentada, destacando-se a modalidade como meio capaz de revelar a 
influência dos contextos de cultura e de situação nas escolhas linguísticas. Segue-se a descrição metodológica do tratamento dos dados e a discussão de excertos que mostram o uso das modalidades mencionadas, finalizando o artigo uma reflexão sobre o que pode ser ensinado e discutido em contextos de ensino da escrita acadêmica.

\section{Pressupostos teóricos}

A importância de centrar-se esta discussão na Linguística SistêmicoFuncional (LSF) está no fato de que, nessa perspectiva teórica, a relação textolinguagem-contexto explica as escolhas linguísticas do sujeito para a produção de significados e o modo como estes são construídos em contextos reais de uso da língua. A partir de três metafunçôes: a ideacional, que possibilita significar as experiências do sujeito no mundo; a interpessoal, para significar as relaçôes sociais nas quais o sujeito se envolve; e a textual, para organizar a mensagem em função das pretensōes do sujeito em uma dada comunidade discursiva, a vertente teórica sistêmico-funcional instrumentaliza-nos para explicar o discurso construído nos mais diversos contextos. Neste trabalho, interessa-nos especificamente compreender as escolhas modais realizadas por pós-graduandos; para tal, a discussão teórica focalizará, inicialmente, o conceito de voz (HYLAND, 2008), por entendê-lo como constituinte relevante do discurso acadêmico, articulandoo ao conceito de modalidade (HENGEVELD, 1988, 1989, 2004; HALLIDAY e MATTHIESSEN, 2004).

\subsection{Noção de voz}

O conceito de voz é central para o estudo da escrita acadêmica, especialmente em se tratando da revisão de literatura, espaço no qual o autor, ao trazer para a tessitura do texto uma voz, sua ou emprestada de outrem, dá lugar à produção de novos significados. Embora muito falemos sobre as vozes do texto, é importante lembrar que na perspectiva sistêmico-funcional essas vozes transmitem representaçôes do escritor, materializadas nas escolhas lexicogramaticais por ele efetuadas a partir de um dado contexto.

Hyland (2008), ao estudar detalhadamente as interações em escrita acadêmica, posiciona-se em relação ao conceito de voz, destacando inicialmente o fato de que nesse tipo de discurso a visão tradicional de voz referindo-se ao modo como autores manifestam pontos de vista, autoridade e presença nos textos cai por terra. O leitor, na academia, não está interessado no ponto de 
vista do autor e em seus posicionamentos e opiniões pessoais, mas em evidências substanciais em relação a o que é dito, que mostrem consonância com as discussões científicas em uma dada comunidade discursiva. $\mathrm{O}$ autor, por sua vez, não escreve apenas para apresentar um dado conteúdo, mas para relacionarse com ele estabelecendo contato com o leitor e com a comunidade discursiva da qual faz parte. Daí considerar-se voz na perspectiva bakhtiniana (BAKHTIN, 1981), correspondendo à consciência do falante presente no enunciado produzido, que, não neutra, revela as percepçōes do sujeito sobre o mundo, sobre o modo como, naquela comunidade discursiva, ele estabelece relações com outros sujeitos.

$\mathrm{Na}$ escrita acadêmica, as relações, nem sempre simétricas, acabam por neutralizar ou até mesmo apagar a personalidade do aluno-autor, marcando um distanciamento entre sua interpretação e a explicação que pode dar sobre os eventos da ciência. Assim, escritores na academia não constroem uma representação de si (HYLAND, 2008, p.6), mas utilizam recursos culturalmente disponíveis quando escrevem, fazendo escolhas para alinhar-se ou desalinhar-se a uma determinada posição ou a outra, dentro de sua comunidade discursiva. Voz não é, portanto, algo opcional no texto, mas sim um modo como o autor posiciona-se em relação a essa comunidade, para dialogar com ela e com seu leitor.

Nesse sentido, a ideia de voz como algo essencialmente social e não pessoal é importante para se compreender os modos de persuasão assumidos pela escrita acadêmica e os modos como estudantes relacionam-se com outros membros de seus grupos, negociando, por meio das escolhas linguísticas, a validade e a credibilidade do que dizem. Hyland (2008, p.7), discutindo esse aspecto, ressalta que escritores na academia, para serem considerados persuasivos, têm de exibir uma competência como insider ao campo de conhecimento, conseguida por meio do diálogo escritor-leitor, realizado no texto a partir do modo como o escritor constrói seu discurso ou, em outras palavras, a partir do metadiscurso.

O termo metadiscurso, na perspectiva de Hyland e Tse (2004, p.157), tem sido usado como um termo guarda-chuva para abarcar um conjunto de recursos coesivos e interpessoais que, possibilitando aos leitores embrenhar-se no texto para conectar-se ao autor, compreender sua organização textual e estabelecer com ele uma relação de solidariedade, ajuda no estabelecimento de relaçôes entre o texto e a comunidade discursiva na qual este foi produzido. Em outras palavras, baseado em uma visão de escrita como engajamento social e comunicativo entre escritor e leitor, o metadiscurso focaliza nossa atenção 
sobre os meios usados por escritores para projetar-se no interior de seu discurso e sinalizar sua atitude em direção tanto ao conteúdo do texto quanto à sua audiência. Como resultado disso, o metadiscurso, visto como manifestação linguística e retórica do autor, tem sido tomado por pesquisadores do discurso de diferentes orientações teóricas, atraídos pela possibilidade de identificar padrões de interação e coesão entre os textos (HYLAND e TSE, 2004, p.156), de modo articulado à noção de modalidade. Destaca-se, nesse sentido, o conceito de modalidade, discutido na seção seguinte.

\subsection{Modalidade como recurso de engajamento}

Muito se tem estudado sobre modalidade, dada a complexidade em defini-la, justamente pelo modo difuso como se comporta nos mais diferentes contextos. Teóricos da linguagem, impulsionados por estudos aristotélicos que já discutiam a modalidade a partir de seu valor lógico -, têm apresentado diferentes categorias para as modalidades linguísticas. Já em seus primeiros estudos, em 1977, Palmer, ao discutir modalidade, advertia para o fato de que se a analisássemos de modo fragmentado, em apenas uma das dimensões pragmática, semântica ou sintática -, fatalmente incorreríamos em dificuldades, pois estaríamos desprezando significados relevantes, somente revelados na confluência dessas dimensões.

Uma das características importantes para se estabelecer a distinção entre modalidade lógica e modalidade linguística é que a primeira permite avaliar proposições e está interessada na proposição, enquanto a segunda permite avaliar partes de proposiçôes e está interessada nas atitudes do falante em relação ao conteúdo da proposição e ao modo como esta é apresentada.

Na perspectiva sistêmico-funcional, as investigações sobre os diferentes usos da modalidade têm priorizado a articulação entre os níveis semântico, sintático e pragmático para explicar as escolhas modais dos falantes/escritores a partir das características contextuais da produção de textos. O sistema de modalidade, ancorado na metafunção interpessoal da linguagem, é responsável por descrever as escolhas lexicogramaticais disponíveis ao falante/escritor para a expressão dos diferentes graus de probabilidade, de usualidade, de obrigação e de inclinação sobre um dado enunciado, marcando os papéis dos sujeitos no curso da interação.

Embora a modalidade indique o grau de comprometimento do falante/ escritor com a verdade do enunciado, codificando, em relação a este, a "atitude do falante” (GIVÓN, 2001, p.130), na escrita acadêmica, como já 
mencionado, essa interpretação nem sempre seria a mais adequada. Como diz Coracini (2007, p.120),

- as marcas modais em si não determinam a priori o ponto de vista do sujeito enunciador nem as interpretações possíveis: sua presença ou ausência aponta apenas para uma possível interpretação do texto;

- as modalidades constituem verdadeiras estratégias retóricoargumentativas, na medida em que pressupóem uma intencionalidade discursiva, não podendo ser isoladas do ato de fala em que estão inseridas.

Se os atos de fala ocorrem em função da situação sócio-comunicativa, pode-se considerar que o uso da modalidade na escrita acadêmica, recurso atenuador ao qual lançam mão os falantes/escritores para a produção do discurso científico, nem sempre é indicador de dúvida ou de incerteza sobre a proposição enunciada, mas, muitas vezes, de reconhecimento da assimetria de papéis e da falta de poder do autor perante sua comunidade discursiva, evidenciando a forte influência dos contextos de situação e de cultura sobre as escolhas linguísticas.

A LSF conduz essa discussão descartando a possibilidade de análises que focalizam, como já dissemos, aspectos isolados da modalidade, detendo-se em apenas uma das dimensões: semântica, sintática ou pragmática. Halliday e Matthiessen (2004, p.146-147) descrevem o sistema de modalidade como um continuum capaz de oferecer ao falante/escritor escolhas linguísticas que transitam entre dois polos - o positivo e o negativo -, para aferir maior ou menor veracidade e credibilidade às proposiçôes enunciadas, apontando diferentes níveis de indeterminação em relação aos enunciados produzidos. No entanto, quando se toma por fundamento a teoria da Avaliatividade, mais especificamente o sistema de Engajamento (WHITE, 2003), cujo foco está em se considerar a perspectiva dialógica heteroglóssica dos recursos linguísticos, a principal motivação para o estudo da modalidade não é a compreensão do valor de verdade assumido por um falante/escritor em relação a uma dada proposição, mas, acima de tudo, o modo como a voz textual mapeia suas relações com as diversas posiçôes de valor trazidas ao jogo comunicativo por meio do texto, ativadas em função dos contextos de situação e de cultura.

O Engajamento (MARTIN e WHITE, 2005) preocupa-se com relaçōes intersubjetivas que envolvem o falante/escritor no texto, a partir da inter- 
relação das noções bakhtinianas de heteroglossia - caracterizada pela multidão de vozes sociais, pelo encontro sociocultural das diferentes vozes e pela forma como essas vozes relacionam-se para surgimento de novas vozes sociais; e de dialogia - caracterizada pelas relações estabelecidas entre o eu e o outro nos processos discursivos instaurados historicamente pelos participantes e nas relações marcadas pelo falante/escritor, fixadas por sua posição de sujeito social, para antecipar, alinhar-se ou desalinhar-se a outras vozes, criando ou não solidariedade com o ouvinte/leitor.

Interessa-nos, portanto, situar a modalidade no sistema de Engajamento. Como macrocategorias, esse sistema considera a contração e a expansão dialógicas: a primeira, responsável por negar ou opor-se a outras vozes, fechando possibilidades de negociação de significados e pontos de vista; a segunda, pela adesão a outras vozes e abertura de possibilidades de negociação de significados e pontos de vista. Essas macrocategorias apresentam subcategorias que marcam as posições do falante/escritor em relação a: contrapor-se a algo, negando ou apresentando contra-agrumentos; propor, confirmando expectativas, endossando ou apresentando pronunciamento em relação a algo; ponderar, apresentando avaliaçóes baseadas em probabilidade e evidencialidade; e atribuir, reconhecendo ou distanciando-se de vozes externas.

Destaca-se neste artigo a subcategoria de ponderação, especificamente a construída pelo recurso linguístico de modalidade. Martin e White (2005, p.104), discutindo essa subcategoria, dizem referir-se a um domínio semântico que tradicionalmente tem sido chamado de "modalidade epistêmica" e "evidencialidade". Os significados realizam-se a partir do uso de auxiliares modais, adjuntos modais, atributos modais, circunstâncias do tipo em minha opinião, e ainda de certas projeçôes com verbos mentais, como acredito que, penso que, dentre outras formas.

Olhando-se para a modalidade na perspectiva tradicional, pode-se dizer que ela indica o compromisso do falante/escritor com o valor de verdade de uma determinada proposição. No entanto, na perspectiva dialógica, como já dito, a primeira preocupação não é com o valor de verdade ou de confiabilidade sobre a proposição, mas com a avaliação subjetiva do falante/escritor, apresentada de modo a indicar uma dentre possíveis alternativas para o significado em um dado contexto discursivo. Formulações textuais dessa natureza podem até indicar ou deixar transparecer a sensação de que o falante/ escritor desconhece a verdade da proposição ou não tem conhecimento suficiente em relação a ela; no entanto, estudos de Myers (1989) já indicavam 
que na escrita acadêmica essa escolha por um discurso pautado na modalidade tem maior relação com o reconhecimento ou não da comunidade discursiva na qual o texto e o falante/escritor estão inseridos. Em síntese, o efeito gerado pelo uso da modalidade epistêmica no texto acadêmico está muito mais relacionado aos significados no plano informacional/experiencial do que no plano avaliativo/interpessoal (MARTIN e WHITE, 2005, p.108), indicando o contexto e a situação experiencial do falante/escritor como responsáveis por ativar os significados realizados no texto. Nessa direção, também se posiciona Fairclough (1992), ao enfatizar que a modalidade caracteriza-se, na comunidade acadêmica, como uma imposição ao falante/escritor, influenciado por seus pares a não apresentar proposições categóricas.

Ampliando essa discussão, as categorias de modalidade propostas por Hengeveld (1988, 1989, 2004), focalizadas neste artigo, destacam-se justamente por articular as dimensões pragmática, semântica e sintática na investigação do elemento modal, possibilitando discuti-lo nas diferentes instâncias da prática social de uso da língua. $\mathrm{O}$ autor propõe a representação da estrutura da oração em camadas, destacando dois níveis de análise: o representacional e o interpessoal. O primeiro, responsável por apresentar o estado das coisas ou o evento, descrevendo-o de tal modo que o ouvinte/leitor seja capaz de reconhecê-lo como real ou hipotético; o segundo, responsável pelo ato de fala, possibilitando ao ouvinte/leitor reconhecer a intenção comunicativa do falante/escritor. Nessa direção, a predicação assume duas funções: no nível representacional, designado pelo próprio termo predicação, o status do evento - o mundo descrito pela estrutura das unidades linguísticas; no interpessoal, designado por proposição, o conteúdo do ato de fala - as intenções descritas pelas unidades linguísticas. Exemplificando:

Ex. 1: Na sua forma atual, considerando as afirmações de Engeström (2002, p.38-39), a TA pode ser sintetizada de acordo com 5 princípios... (DL6)

No nível representacional, tal enunciado pode ser entendido como a caracterização do estado das coisas. "Pode ser sintetizada" é a forma linguística à qual o falante/escritor recorre para descrever ao ouvinte/leitor o evento comunicativo e o status de realidade desse evento: uma teoria (a TA) que se organiza a partir de cinco princípios. Nessa direção, "considerando as afirmaçôes" marca um distanciamento do falante/escritor, não ocorrendo o mesmo no 
exemplo 2, a seguir, cuja expressão modal "pode ser" relaciona-se ao comprometimento do falante/escritor com o conteúdo da proposição.

Ex. 2: Assim, pode ser que uma inferência sobre o texto nem ocorra ou ocorra após novo trabalho em sala de aula... (MC3)

Hengeveld (1988), ao apontar a necessidade de identificar o nível em que atuam os elementos modais e o tipo de entidade que é qualificada pelo modal, destaca três categorias:

- inerente - significados linguísticos por meio dos quais o falante pode caracterizar a relação entre um participante em um estado de coisas e a realidade potencial desse estado de coisas;

- objetiva - significados linguísticos por meio dos quais o falante pode avaliar a realidade de um estado de coisas em termos de seu conhecimento possível sobre o estado de coisas;

- epistemológica - significados linguísticos por meio dos quais o falante pode expressar seu comprometimento em relação à verdade de uma proposição (HENGEVELD, 1988, p.233).

Em outras palavras, a modalidade inerente é indicativa da capacidade, da habilidade ou da volição de um participante em sua relação com a realização de um evento no qual está inserido; a objetiva - epistêmica e deôntica -, indicativa da avaliação do falante/escritor em termos do status de realidade do evento referido na predicação; e a epistemológica - subjetiva e evidencial -, indicativa do nível de comprometimento do falante/escritor com a verdade do conteúdo da proposição enunciada. Em discussão posterior, Hengeveld (2004) aponta dois critérios para a classificação de modalidades: o tipo de alvo da avaliação e o dominio semântico a partir do qual a avaliação é realizada. $\mathrm{O}$ quadro a seguir articula as categorias aos critérios de classificação explicitados nos estudos do autor. 


\section{QUADRO $1^{2}$}

\section{Modalidade na perspectiva de Hengeveld (1988, 1989, 2004)}

\begin{tabular}{|c|c|c|c|c|c|}
\hline \multirow{2}{*}{\multicolumn{2}{|c|}{$\begin{array}{l}\begin{array}{l}\text { Alvo da avaliação (cor- } \\
\text { responde à parte do } \\
\text { enunciado que é } \\
\text { qualificado pelo }\end{array} \\
\begin{array}{l}\text { Domínio modal) } \\
\text { semântico da }\end{array} \\
\begin{array}{l}\text { avaliação(corres- } \\
\text { ponde ao modo como a } \\
\text { avaliação é apresentada) }\end{array}\end{array}$}} & \multicolumn{2}{|c|}{$\begin{array}{l}\text { Modalidade orientada para o } \\
\text { participante (é expressa por } \\
\text { um predicado e afeta a relação } \\
\text { entre um participante do } \\
\text { evento e a realização potencial } \\
\text { desse evento) }\end{array}$} & $\begin{array}{l}\text { Modalidade orientada para o } \\
\text { evento (afeta a descrição do } \\
\text { evento; tem um caráter mais } \\
\text { genérico) }\end{array}$ & $\begin{array}{l}\text { Modalidade orientada para a } \\
\text { proposição (afeta o conteúdo } \\
\text { da proposição, evidenciando } \\
\text { visões e crenças do falante/ } \\
\text { escritor sobre a proposição) }\end{array}$ \\
\hline & & \multicolumn{3}{|c|}{$\begin{array}{l}\text { Objetiva (o falante/escritor emite julgamentos mas não se } \\
\text { responsabiliza por eles; a responsabilidade está no participante } \\
\text { do evento e/ou no status do evento) }\end{array}$} & $\begin{array}{l}\text { Subjetiva (o falante/ escritor } \\
\text { compromete-se com o que é } \\
\text { enunciado) }\end{array}$ \\
\hline \multicolumn{2}{|c|}{ 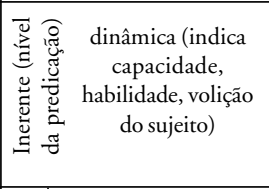 } & \multicolumn{2}{|c|}{$\begin{array}{l}\text { Ex.3: Após a discussão sobre } \\
\text { gêneros, certamente os alunos } \\
\text { poderão realizar a tarefa. } \\
\text { (estarão habilitados a / serão } \\
\text { capazes de realizar a tarefa) }\end{array}$} & $\begin{array}{l}\text { Ex.4: A organização do } \\
\text { congresso favoreceu a } \\
\text { compreensão sobre como se } \\
\text { pode elaborar artigos para } \\
\text { publicação. (como alguém é } \\
\text { capaz de elaborar artigos) }\end{array}$ & \\
\hline \multirow{2}{*}{ 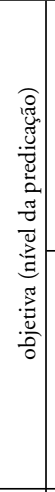 } & $\begin{array}{c}\text { epistêmica (indica o } \\
\text { conhecimento do } \\
\text { falante/escritor sobre } \\
\text { o status de um evento } \\
\text { comunicacional ou de } \\
\text { uma situação } \\
\text { hipotética, em termos } \\
\text { de possibilidades) }\end{array}$ & & & $\begin{array}{l}\text { Ex.5: Os autores defendem } \\
\text { uma tipologia regida por traços } \\
\text { que estejam em um nível } \\
\text { intermediário entre os dois } \\
\text { termos. Tal tipologia pode estar } \\
\text { diretamente relacionada às } \\
\text { estruturas cartográficas ou... } \\
\text { (DS4) }\end{array}$ & $\begin{array}{l}\text { Ex.6: ...elemento ideológico } \\
\text { discursivo de seus enunciados é } \\
\text { analisado e respondido em } \\
\text { alguma medida por seus pares, } \\
\text { gerando uma resposta que pode } \\
\text { ser que ocorra em questão de } \\
\text { pouco tempo... (MC1) }\end{array}$ \\
\hline & $\begin{array}{l}\text { deôntica (indica a } \\
\text { avaliação do falante/ } \\
\text { escritor em relação a } \\
\text { algum sistema de } \\
\text { convençōes morais, } \\
\text { legais ou sociais) }\end{array}$ & $\begin{array}{l}\text { Ex.7: } \\
\text { vivemo } \\
\text { profess } \\
\text { profiss } \\
\text { Posicio } \\
\text { pode a } \\
\text { usando } \\
\text { instrun }\end{array}$ & $\begin{array}{l}\text { contexto em que } \\
\text { s hoje exige que o } \\
\text { sor se assuma como um } \\
\text { ional capaz (...) } \\
\text { nando-se dessa forma, } \\
\text { sscender à sociedade } \\
\text { a educação como } \\
\text { mento de luta (...) (DP2) }\end{array}$ & $\begin{array}{l}\text { Ex.8: Segundo Teberosky } \\
(1994), \text { o ambiente } \\
\text { alfabetizador como ambiente } \\
\text { linguístico não pode ser deixado } \\
\text { de lado (...), pois apenas o } \\
\text { contato com o objeto língua } \\
\text { escrita não garante a } \\
\text { alfabetização. (DP1) }\end{array}$ & \\
\hline \multirow{3}{*}{ 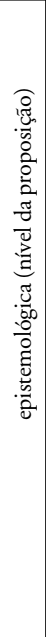 } & \multirow{2}{*}{$\begin{array}{l}\text { subjetiva (o falante/ } \\
\text { escritor se assume } \\
\text { como fonte da } \\
\text { informação contida } \\
\text { na predicação) }\end{array}$} & 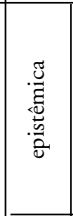 & $\begin{array}{l}\text { Ex.9: Posso dizer que, } \\
\text { embora alunos sejam } \\
\text { capazes da reescrita } \\
\text { (...), nem sempre } \\
\text { podem compreender } \\
\text { suas etapas. (MC4) }\end{array}$ & \begin{tabular}{|l|} 
Ex.10: Agora, o que podemos \\
apontar como fator \\
diferenciador entre o \\
enunciado e o gênero desliza \\
para (...) e pode ser encontrado \\
na menção que Bakhtin faz da \\
inter-dependência... (DM8) \\
\end{tabular} & \begin{tabular}{|l} 
Ex.11: A partir dessa ideia, \\
podemos organizar um \\
pensamento em que a \\
manifestação do gênero ocorre \\
na instância aqui denominada \\
de interno do enunciado. \\
(DM8) \\
\end{tabular} \\
\hline & & 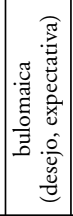 & $\begin{array}{l}\text { Ex.12: As mudanças na } \\
\text { conduta do professor } \\
\text { talvez pudessem } \\
\text { conduzi-lo a maior } \\
\text { autonomia... (DG2) }\end{array}$ & $\begin{array}{l}\text { Ex.13: Tudo isso me leva a crer } \\
\text { que a emoção poderia desenca- } \\
\text { dear, através da relação com } \\
\text { elementos referentes às crenças } \\
\text { e aos conhecimentos dos } \\
\text { sujeitos, determinados tipos de } \\
\text { comportamento. (DM3) }\end{array}$ & $\begin{array}{l}\text { Ex.14: Pode-se sugerir que o } \\
\text { professor discuta sua perspectiva } \\
\text { quanto ao ensino da análise } \\
\text { linguística com seus pares, o que } \\
\text { seria muito interessante, dado } \\
\text { que... (MS6) }\end{array}$ \\
\hline & $\begin{array}{c}\text { evidencial (o falante/ } \\
\text { escritor indica ou não a } \\
\text { fonte de informação, } \\
\text { revelando mais ou menos } \\
\text { comprometi-mento } \\
\text { com o valor de verdade } \\
\text { da proposição) }\end{array}$ & 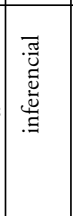 & & & $\begin{array}{l}\text { Ex.15: Quanto ao nível } \\
\text { organizacional, podemos } \\
\text { identificar o plano global do } \\
\text { texto, isto é, a planificação geral } \\
\text { dos conteúdos temáticos, o que } \\
\text { nos permite... (DP5) }\end{array}$ \\
\hline
\end{tabular}

${ }^{2}$ Exemplos marcados com $\mathrm{M}$ ou $\mathrm{D}$ integram o corpus investigado, correspondendo, respectivamente, a Mestrado e Doutorado. Demais exemplos foram criados pela autora. 


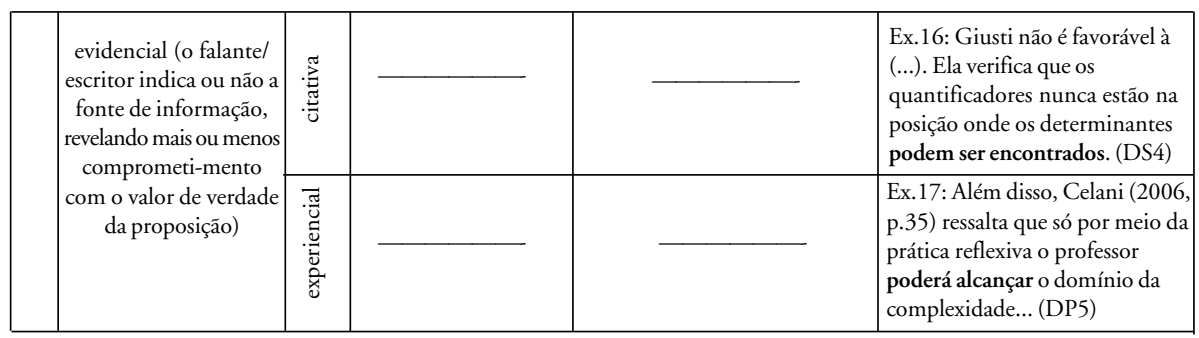

A exemplo de Menezes (2012), que discute a modalidade instaurada na construção do discurso argumentativo e destaca principalmente a deôntica, a opção, neste artigo, é analisar a modalidade voltada ao participante ou ao evento descrito no enunciado.

Ao optar por instaurar uma obrigação que recai apenas indiretamente sobre outrem, uma vez que a indicação dos alvos humanos sobre os quais recai uma obrigação dá-se em referência à esfera institucional à qual pertencem, poupa-se o orador de um confronto direto, o que é estratégia retórica valiosa à construção da persuasão, pois o orador convoca a realizar uma ação ou a evitar que algo se produza sem se indispor pessoalmente. Por sua vez, quando o orador opta por expressão linguística (...) pela modalidade orientada para o evento descrito no enunciado, os alvos humanos sobre os quais recaem os valores semânticos sequer são indiretamente indicados, o que afasta ainda mais o orador do desconforto de um embate com outrem (MENEZES, 2012, p.55).

A escolha por esse tipo de análise deve-se, portanto, ao fato de que nessa perspectiva é possível perceber como a voz autoral está diretamente envolvida com a situação sobre a qual recai a modalidade descrita no enunciado.

\section{Metodologia}

Considerou-se para este estudo um corpus (Tabela 1) constituído de seçōes teóricas de 40 dissertações e 40 teses da área de Letras/Linguística, coletadas de bibliotecas eletrônicas de universidades brasileiras, submetidas ao programa computacional WordSmith Tools 5.0 (SCOTT, 2009). A opção pela análise de seções teóricas das dissertações e teses deve-se ao fato de que é exatamente nelas que o autor mostra sua filiação a uma determinada corrente teórica, em uma certa comunidade discursiva, e, ao explicitar compreensão em relação aos conceitos adotados para sustentar suas discussōes, também estabelece diálogos 
com teorias convergentes e divergentes, aspecto fundamental para a produção do conhecimento científico.

Após mapeamento dos textos (selecionados das instituições apresentadas na Tabela 1) em termos de frequência do léxico, por meio da ferramenta Wordlist, as escolhas mais recorrentes foram agrupadas conforme o tipo de Engajamento. Dada a alta frequência de uso do modal "poder", optou-se por discuti-lo para compreender o grau de engajamento e de atribuição da responsabilidade dos falantes/escritores em relação aos enunciados presentes nos textos.

\section{TABELA 1}

Corpus pesquisado

\begin{tabular}{l|c|c}
\hline Instituição & Dissertações & Teses \\
\hline PUC-SP & 6 & 5 \\
PUC-RS & & 1 \\
UCPEL & & 6 \\
UCS & 6 & \\
UECE & 5 & 2 \\
UFC & & 8 \\
UFMG & & 5 \\
UFPB & & \\
UFRJ & 5 & 2 \\
UFRN & & 5 \\
UFSC & & 1 \\
UFSM & 5 & 3 \\
UNB & 5 & \\
UNICAMP & 3 & 40 \\
UNISINOS & 5 & \\
UNITAU & 50 & \\
\hline TOTAL & & \\
\hline
\end{tabular}

Tabela 2

Características do Corpus

\begin{tabular}{l|r|r}
\hline & Mestrado & Doutorado \\
\hline número de textos & 40 & 40 \\
tamanho do arquivo & 4197849 & 5737651 \\
tokens usados para a wordlist & 594808 & 806650 \\
palavras distintas & 30225 & 35649 \\
\hline
\end{tabular}


As ocorrências do modal "poder" foram agrupadas a partir das linhas de concordância exibidas pela ferramenta Concord, do WordSmith Tools 5.0, de modo a identificar sua função no texto. Uma vez classificadas, foram observados os grupos indicados na tabela 3 , a seguir.

TABELA 3

Uso do modal PODER

\begin{tabular}{l|r|r|r|r|r}
\hline \multicolumn{4}{c|}{ MESTRADO } & \multicolumn{2}{c}{ DOUTORADO } \\
\hline Modal & $\begin{array}{c}\text { Modalidade } \\
\text { (expressão da } \\
\text { Voz Externa) }\end{array}$ & $\begin{array}{c}\text { Modalidade } \\
\text { (expressão da } \\
\text { Voz Autoral) }\end{array}$ & $\begin{array}{c}\text { Modalidade } \\
\text { (expressão da } \\
\text { Voz Externa) }\end{array}$ & $\begin{array}{c}\text { Modalidade } \\
\text { (expressão da } \\
\text { Voz Autoral) }\end{array}$ & Total \\
\hline pode & 352 & 415 & 267 & 797 & 1831 \\
podem & 203 & 194 & 141 & 415 & 953 \\
poderia & 6 & 30 & 4 & 79 & 119 \\
poderiam & 3 & 15 & 9 & 29 & 56 \\
poderá & 2 & 15 & 4 & 25 & 46 \\
poderão & 0 & 14 & 0 & 11 & 25 \\
\hline total & 566 & 683 & 425 & 1356 & 3030 \\
\hline
\end{tabular}

Em termos de domínio semântico da avaliação indicada pelo uso do modal "poder", a tabela 4 sintetiza os resultados encontrados.

TABELA 4

Domínio semântico da avaliação indicada pelo modal PODER

\begin{tabular}{|c|c|c|c|c|c|c|c|c|c|c|c|}
\hline & MS & DO & MS & DO & MS & $\mathrm{DO}$ & MS & DO & MS & DO & \\
\hline & \multicolumn{2}{|c|}{ 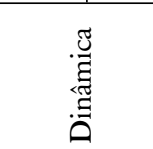 } & \multicolumn{2}{|c|}{ 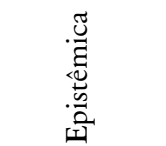 } & \multicolumn{2}{|c|}{ 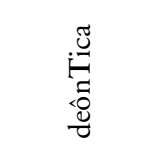 } & \multicolumn{2}{|c|}{$\begin{array}{l}\frac{\pi}{3} \\
\frac{0}{n} \\
\vec{n}\end{array}$} & \multicolumn{2}{|c|}{ 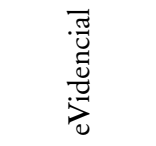 } & 苞 \\
\hline pode & 55 & 37 & 606 & 835 & 106 & 192 & 0 & 0 & 0 & 0 & 1831 \\
\hline podem & 30 & 50 & 327 & 421 & 40 & 85 & 0 & 0 & 0 & 0 & 953 \\
\hline poderia & 0 & 0 & 23 & 72 & 6 & 11 & 8 & 0 & 0 & 0 & 119 \\
\hline poderiam & 0 & 0 & 16 & 20 & 1 & 12 & 1 & 6 & 0 & 0 & 56 \\
\hline poderá & 4 & 2 & 11 & 24 & 2 & 2 & 0 & 1 & 0 & 0 & 46 \\
\hline poderão & 0 & 0 & 13 & 10 & 1 & 1 & 0 & 0 & 0 & 0 & 25 \\
\hline Total & 89 & 89 & 996 & 1383 & 156 & 303 & 9 & 7 & 0 & 0 & 3030 \\
\hline
\end{tabular}

A seção a seguir discute excertos selecionados do corpus, com o propósito de explicar a realização da modalidade nas perspectivas: sintática - formas de expressão no uso do modal "poder" e tempo verbal; semântica-domínio da avaliação de ordem dinâmica, epistêmica, deôntica, subjetiva e evidencial; pragmático-discursiva-marcas de atenuação e asseveração para a produção de significados. 


\section{Análise e discussão de resultados}

Dado o caráter polissêmico do modal "poder", interessa-nos, especificamente, o modo como a voz autoral o utiliza, seja para indicar sua própria avaliação ou creditá-la a uma voz externa, onde mais comumente ocorre o apagamento do autor. É justamente aí que se pode observar os limites tênues da força ilocucionária do enunciado entre ser essa modalidade atribuída à voz autoral ou à voz externa. Como já dito, optou-se por discuti-la, no contexto da escrita acadêmica, analisando-a a partir das categorias apresentadas por Hengeveld $(1988 ; 1989 ; 2004)$, justamente por evidenciarem o papel do falante/escritor em relação à proposição e ao evento comunicacional, e, por outro lado, permitirem discutir a (in) determinação das fronteiras de significado quanto às vozes no texto.

Em relação à modalidade como expressão da voz externa, destacam-se casos de citação em que a modalidade indica a relação entre o autor citado e seus leitores. No entanto, nos casos em que a voz externa é inserida no texto por meio de paráfrases, por exemplo, o que se tem é um recurso modal ambíguo: a modalidade expressa a avaliação da voz externa ou da voz autoral? Um exemplo disso é o que segue:

Ex.18: Para Stratford (1989), Sèguin foi pioneiro em um trabalho educacional que hoje poderia ser considerado como a primeira escola de educação especial da história (...) (DI3)

Poderia, expressão que veicula uma possibilidade negativa, faz emergir a pergunta: a modalidade indicativa de dúvida, de não certeza, é expressa por Stratford? Ou, por outro modo, a modalidade indicativa de dúvida é acrescentada ao texto para expressar posicionamento da voz autoral? Se considerarmos a primeira hipótese, podemos então pensar que, para Stratford, o trabalho de Sèguin remotamente seria considerado como a primeira escola de educação especial da história, significado marcado linguisticamente pelo uso do tempo verbal futuro do pretérito (pretérito condicional). Já a partir da segunda hipótese não nos é possível saber qual a consideração de Sratford a respeito do trabalho de Sèguin. Essa possibilidade remota poderia ser creditada à voz autoral. Enunciados como esse deixam em aberto o significado da modalidade e interessam a este artigo, pois estão relacionados ao modo como ocorre a escrita acadêmica e à compreensão que o aluno-autor tem de voz e de inserção de vozes externas no texto. A questão que se pretende discutir é: como 
esse aluno-autor conscientiza-se de que o modo como apresenta o recurso de modalidade pode interferir no significado efetivo dessa voz externa?

Ao utilizar em seus enunciados a modalidade na articulação com modos de citar ou reconhecer uma voz externa por meio de paráfrases, o aluno-autor, tanto de mestrado quanto de doutorado, deixa ao leitor a tarefa de interpretar a quem cabe a responsabilidade sobre a avaliação da proposição ou do evento. Os exemplos a seguir revelam isso.

Ex.19: ... remete-nos ao conceito vygotskyano de zona proximal de desenvolvimento (ZPD), o qual "reflete (...)". Para Vygotsky, a ZPD pode ser definida como a diferença existente entre o nível do que a pessoa é capaz de fazer com a ajuda de outros e o nível das tarefas que pode fazer de maneira independente (SALVADOR, 2000, p.260). A consideração do conhecimento real apresentado... (MT5)

A modalidade representacional expressa por pode ser é, nesse exemplo, creditada a Vygotsky ou, ainda, ao autor citado, Salvador. O que nos leva a isso é o fato de que o aluno-autor do mestrado parece ter parafraseado a voz de Salvador para apresentar um conceito vygotskyano. No entanto, consultando os originais de Vygotsky e de Salvador et al., vê-se que o conceito é apresentado pelo primeiro do seguinte modo:

Zona de Desenvolvimento Proximal é a distância entre o nível de desenvolvimento real, que se costuma determinar através da solução independente de problemas, e o nível potencial, determinado através da solução de problemas sob a orientaçãpo de um adulto ou em colaboração com companheiros mais capazes (VYGOTSKY, 2000 [1935], p.112).

Já o trecho "Para Vygotsky, a ZPD pode ser definida (...) independente" é dos autores Salvador et al. (2000, p.260); no entanto, é apresentado pelo aluno-mestrando não como uma citação textual, mas como uma paráfrase. A ausência de indicação de citação textual nos leva a crer que o uso da modalidade pode ser está sendo delegada pelo aluno-autor a Vygotsky, mas, na verdade, é apresentada originalmente por Salvador et al.

Outro exemplo nessa mesma direção é o que segue. 
Ex. 20: Para Koch (2002, p.60), pode haver uma definição aproximada da intertextualidade: É nesse sentido que Maingueneau (1976:39) afirma que o intertexto pode ser um componente decisivo das condiçôes de produção: "um discurso não vem ao mundo numa inocente solicitude [sic]... (DC1)

O aluno-autor credita a Koch a modalidade epistêmica orientada para a proposição: pode haver uma definição aproximada da intertextualidade. Parecendo parafrasear Mangueneau, a voz autoral, por meio do recurso de engajamento do tipo reconhecimento, escolhe o processo afirmar, com força ilocucionária categórica, para, em seguida, creditar a Maingueneau a modalidade epistêmica pode ser, orientada para o participante (o intertexto) do evento (ser um componente decisivo nas condições de produção). No entanto, quando se recorre ao texto original de Koch (2000, p.60), o que se tem é:

A intertextualidade em sentido amplo, condição de existência do próprio discurso, pode ser aproximada do que, sob a perspectiva da Análise do Discurso, se denomina interdiscursividade (ou heterogeneidade constitutiva, segundo Authier, 1982). É nesse sentido que Maingueneau (1976, p.39) afirma ser o intertexto um componente decisivo das condições de produção: "um discurso não vem ao mundo numa inocente solitude, mas constrói-se através de um já-dito em relação ao qual toma posição" (KOCH, 2000, p.60).

Em Koch, a modalidade pode ser aproximada representa uma avaliação da própria autora, para indicar que os conceitos de intertextualidade e interdiscursividade mantêm alguma relação afim, percebida quando se recorre às teorias que os embasam. Quando se observa, no entanto, o texto do alunodoutorando, vê-se que a modalidade orientada para uma proposição, creditada a Koch, é indicativa de que a autora argumenta em favor de alguma outra definição de intertextualidade. Descobre-se também que o aluno-doutorando não parafraseou Maingueneau, mas a própria Koch, apenas pela modificação modalizada de afirma ser o intertexto um componente decisivo para o intertexto pode ser um componente decisivo.

Quando se compara o texto analisado ao original do autor nele citado, é possível perceber, muitas vezes, que a pretensão do aluno-autor não era outra senão parafrasear o trecho escolhido, no entanto, essa paráfrase ocorre apenas para inserir o recurso de modalidade na voz citada. O exemplo a seguir ratifica essa questão: 
Ex. 21: Para iniciar a discussão, retomo um questionamento apresentado por Pennycook (1998, p.29): “[...] além da língua em si, do que mais uma aula de língua deve tratar?" Para o autor, a aprendizagem de línguas pode estar intimamente ligada tanto à manutenção das desigualdades sociais, quanto às condiçôes que possibilitam mudá-las. (DP2)

A modalidade epistêmica orientada para a proposição pode estar intimamente ligada... é creditada a Pennycook, mas o que se tem originalmente, desse autor, é:

Também estou convencido de que a aprendizagem de línguas está intimamente ligada tanto à manutenção dessas iniquidades quanto às condições que possibilitam mudá-las (PENNYCOOK, 1998, p.24).

Analisando-se agora por um outro ângulo, o da pretensão de neutralizar sua própria voz, característica marcante na comunidade acadêmica, tem-se diferentes modos de uso da modalidade. Há, por exemplo, enunciados nos quais o autor mestrando ou doutorando apresenta o modal "poder" para indicar possibilidade e, nesse sentido, ao delegar tal modalidade aos autores citados, produz-se um efeito de sentido pretendido por estes - a possibilidade em relação a uma dada proposição. Ainda que seja depositada a responsabilidade pelo uso da modalidade na voz externa, do autor citado, o sentido pretendido para a compreensão da proposição é alcançado. Observa-se isso a seguir:

Ex. 21: Segundo Halliday e Matthiessen (2004, p.3-4), a linguagem pode ser explorada sob muitos pontos de vista, porém podemos distinguir dois ângulos principais de visão... (DP6)

Ex. 22: Segundo Gallo (2001), a autoria pode ser observada em dois níveis no discurso: no primeiro nível, ocorre o caso da função-autor e, no segundo nível, o caso do efeito-autor, que se encontra no nível discursivo... (DC1)

Ex. 23: Bakhtin (ibidem), diferente de Saussure, considera que o leitor ou o sujeito, ao ouvir ou ler, pode concordar, discordar, elaborar, reelaborar e responder. (MS6)

Ex. 24: Segundo Scaramucci (2000/2001), essa desarmonia pode ser causada, dentre outros fatores, pela adoção de um material cujas visóes de linguagem, ensino e aprendizagem sejam diferentes da abordagem do professor. (MM2) 
O exemplo seguinte, 25, apresenta outro uso da modalidade no texto acadêmico: a voz autoral, por meio de modalidade orientada para o evento, credita ao autor citado a avaliação, porém, assume sua participação nessa avaliação, uma vez que tece um comentário, decorrente do evento, epistemicamente modalizado.

Ex. 25: Por outro lado, o mesmo autor destaca que pode acontecer, como é o geral, de que determinado mapa conceitual que um indivíduo traz em sua cabeça seja diferente do mapa conceitual que outro indivíduo porta. Sendo assim, as interpretações do mundo podem ser dadas de maneira completamente distintas, a depender do indivíduo. (MC4)

Já no exemplo a seguir, as modalidades orientadas para um evento e uma proposição, respectivamente, utilizadas para garantir um certo grau de neutralidade à voz autoral, que se contrapóe ao posicionamento de duas vozes externas (Lieblich et al. e Pavlenko), organizam-se para dar uma explicação:

Ex. 26: Tanto Lieblich et al. (1998, p.1-2), como Pavlenko (2007, p.163) discorrem sobre essa dificuldade. No entanto, o que se pode observar é que não existe um "guia" para a análise de narrativas, ao contrário, essas podem ser analisadas de diferentes maneiras, dependendo da natureza da pesquisa que se pretende realizar e do conceito de narrativa que orienta o trabalho. (DM6)

Vale destacar que o movimento de contrapor-se a uma voz externa (no entanto) é o recurso de engajamento (MARTIN e WHITE, 2005) menos utilizado pelos alunos-autores, no corpus analisado. Esperava-se encontrar, principalmente nos textos de alunos-doutorandos, tal recurso, uma vez que é a partir da articulação de diferentes pontos de vista, muitas vezes controversos, que se constrói o conhecimento novo, objeto idealizado das teses de doutorado.

Também em relação à neutralização da voz autoral, o exemplo seguinte apresenta o uso da modalidade, organizada a partir de uma relação condicional:

Ex. 27: Não se trata de equiparar os conhecimentos linguísticos do professor e os do graduando e, sim, de tornar paritárias as posiçôes assumidas pelos sujeitos de conhecimentos. Para mim, o diálogo entre pontos de vista epistemológicos diferentes pode ser mais produtivo se os sujeitos em interação não estiverem hierarquizados em patamares distintos, ou seja... (DL1) 
Nota-se, nesse exemplo, que a modalidade - vista como epistêmica, se o sentido considerado for o de possibilidade, ou como dinâmica, se de capacidade - orientada para o participante (o diálogo entre pontos de vista epistemológicos) constitui-se em um artifício linguístico que "esconde" uma posição mais acertiva do aluno-autor: o diálogo (...) é mais produtivo quando os sujeitos não estão hierarquizados (...), confirmando-se, mais uma vez, a força do contexto de cultura - o da comunidade discursiva acadêmica - nas produções textuais de seus membros.

\section{Considerações}

Pretendeu-se, neste artigo, discutir e problematizar o uso do modal "poder" na escrita acadêmica, mais especificamente, em dissertaçōes e teses da área de Linguística, dado seu alto índice de ocorrências. Como foi possível observar nos exemplos apresentados, o papel exercido pelos contextos de cultura e de situação, associado à característica polissêmica do verbo, exerce influência direta nas escolhas linguístico-discursivas dos alunos-autores, possibilitando a coocorrência de diversas leituras para um mesmo enunciado.

O que se destaca, portanto, como prioridade, além da importância de uma análise que considere as dimensões pragmática, semântica e sintática da modalidade, é que esta possa ser estendida às atividades de ensino, de tal modo que se problematize e discuta, junto aos alunos na academia, a organização das vozes nos textos e o significado da avaliação que resulta do uso da modalidade nos enunciados produzidos especialmente para a inserção de vozes externas, recurso preponderante na escrita acadêmica.

\section{Referências}

BAKHTIN, M. Marxismo e filosofia da linguagem. São Paulo: Hucitec, 1981.

BESSA, J.C.R.; BERNARDINO, R.A. dos S. A referência ao discurso do outro em textos acadêmicos de estudantes de curso de Letras/Português. Anais do VII Congresso Internacional da ABRALIN, Curitiba, 2011, p.2068-2081. Disponível em: <http://www.abralin.org/abralin11_cdrom/artigos/Jose_Cezinaldo_Bessa. PDF> Acesso em: 18 mar. 2012.

BEZERRA, B.G. A organização retórica de resenhas acadêmicas. Linguagem em (Dis)curso - LemD, Tubarão, v.3, n.1, p.37-68, jul./dez. 2002.

CORACINI, M.J. Um fazer persuasivo. O discurso subjetivo da ciência. $2^{\mathrm{a}}$ ed. Campinas, SP: Pontes, 2007. 
FAIRCLOUGH. Discourse and Social Change. Cambridge: Polity Press, 1992. FIAD, R.S. A escrita na universidade. Revista da ABRALIN, v.Eletrônico, p.357369, $2^{a}$ parte, 2011. Disponível em: <http://www.abralin.org/revista/RVE2/ 14v.pdf> Acesso em: 08 fev. 2013.

FIGUEIREDO, D. de C.; BONINI, A. Práticas discursivas e ensino do texto acadêmico: concepções de alunos de mestrado sobre a escrita. Linguagem em (Dis)curso - LemD, Tubarão, v.6, n.3, p.413-446, set./dez. 2006.

GIVÓN, T. Tense, Aspect and Modality I: functional organization. In:

Syntax - an Introduction, v.1. Amsterdam; Philadelphia: J.Benjamins Publishing Company, 2001, p.285-335.

HALLIDAY, M.A.K. An Introduction to Functional Grammar. London: Edward Arnold, 1985.

HALLIDAY, M.A.K. An Introduction to Functional Grammar. $2^{\text {nd }}$ ed. London: Edward Arnold, 1994.

HALLIDAY, M.A.K.; MATTHIESSEN, C.M.I.M. An Introduction to Functional Grammar. $3^{\text {nd }}$ ed. London: Edward Arnold, 2004.

HENGEVELD, K. Illocution, Mood and Modality in a Functional Grammar of Spanish. Journal of Semantics, 1988, v.6, p.227-269.

HENGEVELD, K. Layer and Operators in Functional Grammar. Journal of Linguistics, 25, 1989, p.127-157.

HENGEVELD, K. Mood and Modality. In: BOOIJ, G.; LEHMANN, C.; MUGDAN, J. (Ed.). Morphology: a handbook on inflection and word formation. Berlin: Mouton de Gruyter, 2004. v. 2, p.1190-1202.

HYLAND, K. Disciplinary Voices - interactions in research writing. English Text Construction. John Benjamins Publishing Company, 2008. p.5-22.

HYLAND, K.; TSE, P. Metadiscourse in Academic Writing: a reappraisal. Applied Linguistics, 25/2, p.156-177. Oxford University Press, 2004.

MACEDO, T.S. de; PAGANO, A.S. Análise de citações em textos acadêmicos escritos. DELTA: Documentação de Estudos em Linguistica Teórica e Aplicada. v. 27, $\mathrm{n}^{\circ}$ 2, São Paulo, 2011. Disponível em: <http://www.scielo.br/scielo.php?pid= S0102-44502011000200004\&script=sci_arttext> Acesso em: 17 out. 2012.

MARTIN, J.R. Beyond Exchange: appraisal systems in English. In: HUNSTON, S.; THOMPSON, G. (Ed.) Evaluation in Text: autoral stance and the construction of discourse. Oxford: OUP, 2000.

THOMPSON, G.; WHITE, P.R.R. The Language of Evaluation: appraisal in English. New York: Palgrave Macmillan, 2005. 
MENDES, R. dos S. A importância da adequada estruturação de resumo e resenha. Revista Espaço Acadêmico, no 114, nov. 2010. Disponível em: <www.periodicos.uem.br/ojs/index.php/EspacoAcademico/.../6251> Acesso em: 14 dez. 2012.

MENEZES, L.C.de. Por um entendimento retórico-funcional da categoria modalidade em função argumentativa. Fórum Linguístico, Florianópolis, v.9, n.1, p.47-56, jan./mar. 2012. Disponível em: <.http://dx.doi.org/10.5007/19848412.2012v9n1p47 > Acesso em: 21.maio.2013.

MOTTA-ROTH, D. (Org.) Redação acadêmica: princípios básicos. Santa Maria: Imprensa Universitária, 2001.

MOTTA-ROTH, D. A construção social do gênero resenha acadêmica. In: MEURER, J.L.; MOTTA-ROTH, D. (Org.) Gêneros textuais: subsídios para o ensino da linguagem. Bauru: EDUSC-Editora da Universidade do Sagrado Coração, 2002.

MOTTA-ROTH, D. O ensino de produção textual com base em atividades sociais e gêneros textuais. Linguagem em (Dis)curso. LemD, Tubarão, v.6, n.3, p.495-517, set./dez. 2006.

MOTTA-ROTH, D.; HENDGES, G.R. (Org.) Produção textual na universidade. São Paulo: Parábola Editorial, 2010. (Estratégias de Ensino; 20)

MOTTA-ROTH, D.; LOVATO, C.S. O poder hegemônico da ciência no discurso de popularização científica. Caleidoscópio, v.2, n. 3, p.251-268, set./ dez. 2011.

MYERS, G. The Pragmatics of Politeness in Scientific Articles. Applied Linguistics, 10/1, p.1-35. Oxford University Press, 1989.

NININ, M.O.G. Investigação sobre o texto acadêmico: engajamento em trabalhos de mestrado. In: Anais do SIELP. v.2, n.1, Uberlândia: EDUFU, 2012. ISSN 2237-8758. Disponível em: <http://www.ileel.ufu.br/anaisdosielp/pt/ arquivos/sielp2012/1436.pdf> Acesso em: 20 jan. 2013.

OLIVEIRA, J.V.C. O discurso relatado como forma de posição identitária no gênero monográfico: reflexōes para a atividade de revisão de textos. ReVeLe, n.2, jan. 2011. Disponível em: <http://www.letras.ufmg.br/cpq/revista\%20revele/ revista_dois/JAIRO\%20CARVALHAIS\%20-\%20O\%20DISCURSO\% 20RELATADO.pdf> Acesso em: 03 fev. 2013.

SALVADOR, C.C. et al. Psicologia do Ensino. Trad. e Superv. Cristina Maria de Oliveira. Porto Alegre: Artes Médicas Sul, 2000.

SCOTT, M. WordSmith Tools 5.0. Software for text analysis. Oxford: Oxford University Press, 2009. 
SILVA, E.C.F. da. A modalização como persuasão no discurso das introduções de dissertações de mestrado. The ESPecialist. v.30, n.2 (175-191), 2009.

SOUZA, G.S.de; BESSA, J.C.R. A produção textual no ensino superior: análise de processos argumentativos em justificativas de monografias de graduação. Veredas. Atemática, 1/2011, p.305-320, PPG Linguística/UFJF - Juiz de Fora. UYENO, E.Y. Letramento acadêmico, autoria e alteridade: um olhar sobre o (o)outro da escrita. Caminhos em Linguística Aplicada. UNITAU - Universidade de Taubaté, v.1, n.1, 2009. Disponível em: <http://periodicos.unitau.br/ojs2.2/index.php/caminhoslinguistica/article/viewFile/899/717> Acesso em: 14 jan. 2013.

VIAN JR.; O.; IKEDA, S.N. O ensino do gênero resenha pela abordagem sistêmico-funcional na formação de professores. Linguagem \& Ensino. Pelotas, v.12, n.1, p.13-32, jan./jun. 2009. Disponível em: <www.rle.ucpel.tche.br/ index.php/rle/article/download/88/60> Acesso em: 15 jan. 2013.

WHITE, P.R.R. An Introductory Course in Appraisal Analysis. Appraisal website. 2010. Disponível em: <http://www.grammatics.com/appraisal> Acesso em: 20/ 06/2012.

WHITE, P.R.R. Beyond Modality and Hedging: a dialogic view of the language of intersubjective stance. Text 23(2) 2003, p.259-284.

WILSON, V.; ABREU, A.R. Letramento acadêmico: a construção da paráfrase em resenhas. SOLETRAS, ano X, n.20, jul./dez. 2010. São Gonçalo: UERJ, 2010. Disponível em: <http://www.filologia.org.br/soletras/20/07.pdf> Acesso em: 08 fev. 2013. 